\title{
STRATEGIC REFERENCE POINTS, RISK AND STRATEGIC CHOICES IN SMALL AND MEDIUM-SIZED ENTERPRISES
}

\author{
Ana María García-Pérez ${ }^{1}$, Vanessa Yanes-Estévez ${ }^{2}$, \\ Juan Ramón Oreja-Rodríguez ${ }^{3}$
}

Instituto Universitario de la Empresa (IUDE), Departamento de Economía y Dirección de Empresas, Facultad de Ciencias Económicas y Empresariales,

Universidad de La Laguna, Spain

E-mails: '1angape@ull.es; ${ }^{2}$ vayanes@ull.es (corresponding author),3joreja@ull.es

Received 08 February 2012; accepted 06 August 2012

\begin{abstract}
This article presents a realistic view of the strategic process in small and medium-sized enterprises (SMEs). The study integrates prospect theory and strategic reference point theory: strategic choices depend on how the decision maker perceives the situation in relation to the reference and the risk being taken. Applying Rasch models to a sample of firms in the Canary Islands (Spain), the results show that SMEs that are more influenced by external references take higher risks. These enterprises differ in their strategic choices from those that do not focus on external references in the greater importance they attach to market diversification. This study is pioneer in considering the internal and external dimension of references that SME managers have in mind and linking them, via prospect theory (Kahneman, Tversky 1979), to the risk they take in their strategic choices. It also has the added value of applying Rasch Measurement Theory.

For managers, the study of the SRPs shows a large number of enterprises with a more internal than external view. Thus, the need for rethinking their SRPs and for designing a greater market orientation of firms in the service sector is worth highlighting.

There are also important implications for the public administration and institutions. They should emphasize the promotion of cooperation among enterprises to increase their external orientation and then, the importance of external SRPs. Training, financial and organizational support could be some of the strategies that ought to be implemented.
\end{abstract}

Keywords: Strategic reference point; strategic risk; strategic choice; Rasch model; small and medium-sized enterprises; prospect theory; strategic management.

Reference to this paper should be made as follows: García-Pérez, A. M.; Yanes-Estévez, V.; Oreja-Rodríguez, J. R. 2014. Strategic reference points, risk and strategic choices in small and medium-sized enterprises, Journal of Business Economics and Management 15(3): 562-576.

JEL Classification: M19.

\section{Introduction}

This study describes how firms make strategic decisions, emphasizing the role of managers and their perceptions and cognition (for example, Das, Teng 1999; Helfat, Peteraf 2014). Specifically, it fills a gap in the literature by integrating two relevant approaches 
of strategic management literature: prospect theory (Kahneman, Tversky 1979) and strategic reference point (SRP) theory (Fiegenbaum et al. 1996).

Prospect theory (Kahneman, Tversky 1979) proposes that the references taken into account determine individuals' decisions and the level of risk they take. A reference can be any psychologically important specific point of comparison (Heath et al. 1999). Based on this approach, SRP theory (Fiegenbaum et al. 1996) analyses SRPs' nature and defines them as the references firms use to evaluate decisions or make their strategic decisions (Bamberger, Fiegenbaum 1996).

This line of thought increases understanding of why organizations under identical circumstances adopt different strategic behaviours. The justification for that is that those companies with different strategic behaviours and under identical circumstances tend to: focus their attention on different SRP groups and/or perceive their situation differently with respect to these SRPs (Bamberger, Fiegenbaum 1996).

Integrating prospect theory (Kahneman, Tversky 1979), which explains individuals' attitude to risk according to their references, and SRP theory (Fiegenbaum et al. 1996), shaper of the firm's strategic space (Lavie, Fiegenbaum 2003), reflects the important connection between the role of the individual and the role of the firm in the organizational strategic behaviour. Besides that, "the individual aspirations of top managers and the aspirations of organizations are inextricably linked, but not necessarily aligned" (Shinkle 2012).

Taking SMEs as units of analysis can resolve the debate between what is individual and what is organizational. In these enterprises, the decision maker's cognitive factors drive the firm's strategic behaviour (Osiyevskyy, Dewald 2014) because top managers tend to concentrate the power of strategic decision making (Escribá-Estévez et al. 2008; Jansen et al. 2011).

In this type of organization, strategic choices are then more determined by the perceptions (reference points) of the decision maker than by formal, objective analysis and diagnosis of the firm's situation (Parnell et al. 2000).

This work aims to: (1) identify SRPs' influence on SMEs and classify them according to their level of influence, (2) assess the strategic risk level taken by these enterprises according to SRP influence, and (3) identify the strategic choices of the enterprises to determine if they agree with the risks the decision makers' take according to these influences.

The main contribution of this article is in the framework that links what the manager has in mind (perceptions and attitude) to the strategic choice he makes for his firm. In particular, this study is pioneer in operationalizing SRP theory (Fiegenbaum et al. 1996) by considering the internal and external dimension of references that managers have in mind and linking them, via prospect theory (Kahneman, Tversky 1979), to the risk they take in their strategic choices. It is in the case of SMEs when the application of this theoretical approach makes most sense, as it is the solution to some criticism that have been made about this framework, especially about the research method used in prospect theory (Kahneman, Tversky 1979). For example, when prospect theory (Kah- 
neman, Tversky 1979) is applied to larger firms, decision making in groups will have to be considered, which is very different from the dynamic of individual decision making (Nwogugu 2005) proposed by this theory and quite common in SMEs.

Another contribution of this study is the application of the Rasch Rating Scale Model (Andrich 1988), used in a pioneering way to study enterprises' strategic decision making processes.

This paper has five parts. After this introduction, the second section presents the theoretical background and the hypotheses. Next, the methodology section highlights the application of the Rasch method (1980). The fourth section presents the results. Finally, the fifth part offers conclusions, implications of this study and possible future lines of research.

\section{Theoretical background}

\subsection{Prospect theory: strategic risk and strategic choice}

Prospect theory (Kahneman, Tversky 1979) has made a key contribution by showing that individuals' choices will be more or less risky depending on how they perceive their situation with regard to the reference they have in mind. When they perceive their situation is above or better than the reference, they consider the situation as a gain and develop a risk-averse behaviour. They prefer to be conservative as they are afraid that they may lose their privileged position. On the contrary, if they perceive the situation as a loss situation, as it is lower than the reference, they will display risky behaviour. On this occasion, they trust in the slight possibility of obtaining some profit because they are already in a difficult situation. This asymmetry between risky behaviour and risk-averse behaviour according to the perception of a reference point has meant a great advance in the explanation of individuals' decision making behaviour. In Kahneman and Tversky's (1979) prospect theory, risk is the link par excellence between the firm's situation with respect to its references and the strategic choices it makes.

Risk is one of the most complex concepts in the literature. Decision makers' risk conception does not coincide on many occasions with that formulated by theorists and is even divergent among sectors or types of firms (Shapira 1994). Risk analysis and management can only be as exact as its perception and quantification by the people involved (Williams 1995). Results from previous studies show the need to measure risk as managers experience it (Holmes et al. 2011; McNamara, Bromiley 1999). Thus, much recent research on risk has focused on cognition and perception (Janney, Dess 2006). This study also regards risk, as the decision maker perceives it, that is, the level of risk he thinks he has taken.

\subsection{Strategic reference point theory}

Given that prospect theory (Kahneman, Tversky 1979) places great importance on references, SRP theory (Fiegenbaum et al. 1996) studies in depth the nature of such references in organizations. A reference could be any value subjectively selected for comparing, classifying and evaluating the possible outcomes associated with a decision 
(Wang 2008). SRPs are the result of focusing attention on a piece of information, ignoring other less relevant information and of interpreting data or events (Ginsberg 1990). Thus, SRP theory treats managers as active agents (Kotlar et al. 2014) that select the references (Shinkle 2012).

Fiegenbaum et al. (1996) integrate different theoretical contributions and propose a three-dimensional view of SRPs: an internal dimension delimited by inputs (capacities of the firms) and outputs of the firm (results of the firms' operations); an external dimension defined by customers, suppliers, stakeholders and competitors; and a third dimension that is temporal and represents an orientation to the firm's past, the present and/or the future.

Some studies have investigated a sector's strategic development patterns (Jones, Kashlak 2001) to study the dominant strategic positioning of multinational corporations (Lavie, Fiegenbaum 2003) or to analyse the absorptive capacity of stocks to improve performance (Lev et al. 2009). This proliferation of works, mainly theoretical, on SRPs in recent times, indicates their increasing importance, the need to integrate these references in the studies of firms' strategic decision making processes and above all, the need to make them operative.

Taking the theoretical bases presented, prospect theory (Kahneman, Tversky 1979) and SRP theory (Fiegenbaum et al. 1996), this study considers that if a firm is placed above its SRPs and perceives the situation as profitable, SRPs will not influence its behaviour, as it wants to remain as it is, taking only a slight risk with more conservative actions. To the contrary, SRPs will influence a firm that is below its SRPs and perceives the situation as a loss. Therefore as it wishes to reach them, it seeks opportunities to take greater risks with more risky strategies (Table 1).

Table 1. Strategic decisions: SRPs, risk and choices

\begin{tabular}{lll}
\hline $\begin{array}{l}\text { 1) Influence of } \\
\text { internal/external SRPs }\end{array}$ & 2) Risk taken & 3) Strategic choices \\
\hline $\begin{array}{l}\text { Low influence } \\
\text { of internal/external SRPs }\end{array}$ & Aversion to risk & Conservative choices \\
\hline $\begin{array}{l}\text { High influence } \\
\text { of internal/external SRPs }\end{array}$ & Risk taker & Risky choices \\
\hline
\end{tabular}

Note: 'SRPs' temporal dimension has not been considered in this work.

Source: adapted from prospect theory (Kahneman, Tversky 1979) and SRP theory

(Fiegenbaum et al. 1996).

The idea of more or less influence of SRPs on risk, according to the previous reasoning based mainly on prospect theory (Kahneman, Tversky 1979), leads to the following two hypotheses:

H1: firms that perceive more influence of internal SRPs perceive they take greater risks than those that perceive less influence of internal SRPs.

H2: firms that perceive more influence of external SRPs perceive they take greater risks than those that perceive less influence of external SRPs. 
Relating SRPs' influence on strategic choices according to the level of risk taken and following the approach of prospect theory (Kahneman, Tversky 1979), we propose the hypotheses 3 and 4:

H3: firms that perceive more influence of internal SRPs are the ones that give more importance to more risky strategic choices; firms that perceive less influence of internal SRPs are the ones that give more importance to less risky strategic choices.

H4: firms that perceive more influence of external SRPs, are the ones that give more importance to more risky strategic choices; firms that perceive less influence of external SRPs firms, are the ones that give more importance to less risky strategic choices.

\section{Research methodology}

\subsection{Data collection}

The geographical field of this work is the Canary Islands (Spain). It is a region whose business network is characterized by high fragmentation, as shown by the fact that $46 \%$ are microfirms and $83 \%$ of the firms in the Canary Islands belong to the service sector (Confederación Canaria de Empresarios 2006).

The information used in this study was obtained by means of a questionnaire answered by people with strategic responsibilities or with global knowledge of the SMEs between February and June 2006.

Due to the impossibility of knowing the size of such a population, a non-probability sampling method can be used in special situations when information is lacking (Neuman 1997), as in this case. Furthermore, convenience sampling (Neuman 1997; Zikmund et al. 2010) was chosen as it is recommended for obtaining a large number of completed questionnaires quickly and economically, particularly when other means of obtaining a sample are impractical (Zikmund et al. 2010).

The initial sample was made up of 207 SMEs, classified according to the number of employees and the segments that the Recommendation of the European Committee of 6 May 2005 (DOCE 20.05.2003) established. The sample initially considered was made up of microfirms (43\%), small firms (41\%) and medium-sized firms (16\%). Almost $38 \%$ of the enterprises belonged to the commercial sector, while $42 \%$ are in the other services sector and $20 \%$ are in the industry and construction sectors.

After analyzing validity measurements, final samples of 183 enterprises and 174 enterprises were obtained for the analysis of internal and external SRPs, respectively. In the study of strategic choices, the final samples consisted of 155 enterprises and 152 enterprises to analyse the influence of their internal and external SRPs, respectively.

\subsection{Rasch models (1980)}

The application of Rasch models (1980) in the area of business administration and management (for example, García-Pérez et al. 2012; Salzberger 2009) is one of the 
most recent methodological contributions in this field, after its widespread use in other disciplines.

Its use avoids researchers assuming certain characteristics derived from the application of Likert type scales. The commonly accepted suppositions Rasch methodology (1980) solves are (Fischer et al. 2006): (1) that all the items have the same impact on the scoring of the scale and (2) that all the categories maintain the same distance from the adjacent category. Thus, Rasch models (1980) constitute the only available technique for the construction of linear measures (Bond, Fox 2007) from ordinal observations (Linacre 2004).

Another advantage of the application of Rasch models (1980) is not having to assume that data follow a normal distribution (Engelhard 1984), as it is a model that focuses on the level of individual analysis, as do more general IRT-models. Moreover, another important reason to apply the Rasch model is its parameter separation ${ }^{1}$. The algebraic separation of parameters ensures that, in this study, the equations for estimating item parameters do not involve the enterprise parameters and the equations for estimating enterprise parameters do not involve the item parameters (Wright, Stone 1999).

Rasch methodology also places special emphasis on the model, as it is the data that have to fit to a model. This model is an ideal Rasch methodology model designed from the sample data and fulfilling the desirable characteristics of the measurements (Engelhard 1984), such as being linear and reproducible (Wright, Mok 2004). It is also possible to identify those individuals and variables that do not follow this ideal model and that generate misfits.

One of the main requirements of Rasch models (1980) is the unidimensional character of the measures (Wright, Stone 1999). These measures are assumed to reflect only one feature of the concept being studied, without being affected by any other aspects.

The model used in this work is the Rasch Rating Scale Model. This model was developed by Andrich (1988) specifically for the treatment of information from ordinal multiple category score scales, such as Likert type scales. The parameters are estimated by the maximum likelihood method, using the Winsteps program (Linacre 2007), which considers the PROX and JMLE algorithms (joint maximum likelihood estimation).

\subsection{Measurement scales}

\section{Strategic reference points and risk}

To identify the most and least influential internal and external SRPs on the management of the firm a scale for each type of reference was developed. Both scales are the results of literature review, discussion among researchers and experts in each of the different areas of study and the experience obtained from the people interviewed. The participants in the study answered a question about the influence they perceive on the management of their firm of each item, ranging from 1 (low influence) to 5 (high influence).

1 This justification for the application of Rasch models was proposed by one of the anonymous reviewers of this article. 
The internal references scale included the following items:

- Influence on human resource management (INPUTS) of motivation; Employee satisfaction; Absenteeism; Turnover; Training for the job; Resistance to change; Identification with the firm; Participation in decision making; Participation in the setting of objectives; Autonomy of decision in the performance of your work; Initiative in your work and Control over your work.

- Influence on the achievement of objectives (OUTPUTS) of managerial efficacy; Style of decision making; Information system; Communication system; Participation in decision making and Control process.

The external references include variables of the general and task environment (Porter 1980):

- Influence on the management of your firm of belonging to the European Union; Inflation; Interest rates; Technological change; Unemployment; Euro exchange rate; Change in labour regulations; Labour costs; Taxation; Municipal administration policy; Business associationism; Access to external training courses; External consultancy services; Availability of communications media; Slowness of the Administration; Trading law (trading hours); Change of type of trade; Consumer protection and Consumption habits.

- Influence on the management of your firm of pressure from suppliers; Pressure from distributors; Pressure from end customers; Substitutive products; Current competitors and Threat of new competitors.

The measurements were evaluated according to the Rasch methodology. The reliability of internal and external SRPs measures was analyzed both for enterprises and scale items. The levels obtained were satisfactory to carry out the analysis, according to Nunnally $(1987)^{2}$.

At a global level, the model validity is adequate for both scales. In the individual analysis, 24 and 33 enterprises were eliminated from the calculation of the internal and external SRPs, respectively, as their values generated significant misfits for the model (Linacre 2002). It was only necessary to eliminate three items from the internal SRPs (absenteeism, turnover and training for the job). These characteristics show both the global and the individual validity of the model with the fit of each item and enterprise.

The unidimensional character of the measures required for the application of Rasch models (1980) is analyzed with several indexes: reliability and data fit, the Point-measure correlations (PTMA) ${ }^{3}$ and the Rasch-residual-based principal components analysis $(\mathrm{PCAR})^{4}$. From such indexes, and following Linacre (2007), the authors conclude that, there is some indication that the unidimensionality might not be met perfectly, but to all intents and purposes the validity of the measurement is not seriously threatened and the measures of both internal and external SRPs are essentially unidimensional.

2 The indexes of reability and validity of measurements are available for the interested readers.

3 Point-measure correlation (PTMA) is the correlation between the observations on an item and the corresponding person measure, or vice-versa (Linacre 2007).

4 Rasch-residual-based principal components analysis (PCAR) shows contrasts between opposing factors, not loadings on one factor (Linacre 2007). 
This paper also analyzes the strategic risk level taken by the decision maker from Kahneman and Tversky's (1979) perspective. The individuals indicate the risk level they have taken in decision making. This risk is considered a unidimensional one-item construct. In this way, they assess the level of risk they perceive they have taken. The answer is quantified from 1 (low risk taken) to 5 (high risk taken).

\section{Strategic choices}

The strategic choices considered include items related to growth, market, products, customers and human resources:

- Growth choices: Internal development; Takeovers, Mergers and acquisitions; Strategic alliances; Stability; Survival; Restructuring and Firm size decrease.

- Market choices: Market diversification; Entry to new markets; Market concentration; Market control and Market share increase.

- Customer choices: Customer satisfaction; Quality of service and Customer loyalty.

- Product choices: Quality; Cost reduction; Product specialization, Product diversification; Product differentiation; Development (expand the service) and Product standardization.

- Human resources choices: Job stability; Job flexibility; Quality at work; Labour cost decrease; Outsourcing and Improved professional training.

This question is quantified by the managers interviewed on a scale of 1 if it is a strategic choice of no importance to 5 if it is very important for the firm.

Table 2. Strategic choices according to risk

\begin{tabular}{ll}
\hline \multicolumn{1}{c}{ More risky choices } & \multicolumn{1}{c}{ Less risky choices } \\
\hline Takeovers & Internal development \\
Mergers and acquisitions & Stability \\
Strategic alliances & Survival \\
Restructuring & Market control \\
Firm size decrease & Market share increase \\
Market diversification & Customer satisfaction \\
Entry to new markets & Quality of service \\
Market concentration & Customer loyalty \\
Product specialization & Quality \\
Product diversification & Development (expand the service) \\
Product differentiation & Product standardization \\
Labour cost decrease & Job stability \\
Outsourcing & Job flexibility \\
& Quality at work \\
& Improved professional training \\
& Cost reduction \\
\hline
\end{tabular}

Furthermore, to find out a priori how risky the above strategic choices are, a panel of 22 experts with wide experience in a range of areas of business management was used. These experts evaluated the level of risk associated with each strategic choice ( 1 being not at all risky and 5 very risky). The results have allowed us to create an $a d$ hoc clas- 
sification shown in Table 2. A group of higher than average risk strategic choices and a lower than average one were identified by the experts.

The analyses carried out meet the requirements of measurement reliability.

With regard to the unidimensional character, the same indexes previously mentioned were used. In the analyses of enterprises' strategic choices, the presence of a second dimension opposed to the main one is observed. In order to achieve the desirable unidimensional character, the strategic choices that constitute such second dimensions were eliminated from the analyses.

In the study of strategic choices made depending on internal SRPs' influence, the second dimension, made up of quality of service, quality at work, customer satisfaction and job stability, was eliminated. In the analysis of the strategic choices according to external SRPs' influence, the items corresponding to quality of service, quality at work, quality and customer satisfaction were eliminated. The results are derived from the analyses without the above items, thus the unidimensional character of the measures can be accepted.

\section{Results}

\subsection{Strategic reference points}

To obtain the level of influence enterprises perceive of their SRPs, the analyses include two applications of the Rasch Rating Scale Model (Andrich 1988): one application with the information of internal SRPs and the other with external SRPs. The measurements provided by such a model on SRPs allow us to classify enterprises according to the influence they perceive from their internal and external references in the following, not mutually exclusive, groups:

1) Enterprises according to the influence of internal SRPs (Group 11 and Group 2I): firms that perceive higher influence of internal references (Group 1I) and lower influence of internal references (Group 2I ) on the management of the firms, considering zero in measurement to split the sample into the two groups. The first group consists of 158 enterprises and the second of 25 enterprises. According to previous theoretical reasoning, the first group would be below SRPs, thus perceiving the situation as a loss and taking risks according to Kahneman and Tversky's (1979) prospect theory. The second group would be above the SRPs, having surpassed them in a profit situation and as a result, are risk-averse (Kahneman, Tversky 1979).

2) Enterprises according to the influence of external SRPS (Group 1E and Group 2E): firms that perceive higher influence of external references (Group 1E) and lower influence of external references (Group 2E) on their strategic behaviour, considering zero in measurement to split the sample into the two groups. The first group is made up of 109 enterprises and the second group is composed of 65 enterprises The first group would be below SRPs, thus perceiving the situation as a loss and taking risks according to Kahneman and Tversky's (1979) prospect theory. The second group would be above the SRPs, having surpassed them in a profit situation and as a result, are risk-averse (Kahneman, Tversky 1979). 


\subsection{Strategic risk}

This research analyses strategic risk by comparing the risk taken by the enterprises of Group 1I and Group 1E (more influenced by SRPs, both internal and external, respectively) and Group 2I and Group 2E (less influenced by SRPs, both internal and external, respectively). The statistical results from the Mann Whitney non-parametric test indicate that only the enterprises with high and low influence of external SRPs (Group $1 \mathrm{E}$ and Group 2E, respectively) have a statistically significant difference between the risk their decision makers think they take (Mann-Whitney U-test: 12520.5; W of Wilcoxon: 4536.5; Z: -2.777 ; Asymtotic sig. (bilateral) .005). Thus, the study confirms hypothesis 2 because the more external influence they perceive (Group 1E), the higher risk the managers take as shown by the ranges (Group 1E average range: 92.72; Group $2 \mathrm{E}$ average range: 72.01$)$. However, this is not true for the risk taken by the firms that perceive higher versus lower influence of internal SRPs (Group 1I and Group 2I), and hypothesis 1 is rejected.

This result indicates that only the managers who look outside their firms feel they take risks in a different way from those managers that do not. These decision makers could have a more proactive and innovative strategic attitude than those who do not look outside their firms. Among the decision makers that internal SRPs influence more and those they influence less (Group 1I and Group 2I), there are no differences in their attitude to risk (Mann-Whitney U-test: 1572.500; W of Wilcoxon: 1872.50; Z: -1.224 ; Asymtotic sig. (bilateral) .221). Therefore, they cannot have different positions in their strategic choices.

\subsection{Strategic choices}

For the identification of the differences in the importance of the strategic choices of the groups of firms (Table 3), the study applied the analysis of the differential functioning (DIF) of strategic choices, another tool the Rasch methodology (1980) provides. The DIF indicates that one group of respondents is scoring better than another group of individuals on an item (Linacre 2007). A hypothesis test determines if the difference of the measures of the items in each group of individuals is significant, considering a significance level of 0.05 . In this study, to test hypotheses 3 and 4 , the aim is to identify statistically the possible differences existing between the strategic choices of the firms that perceive high and low influence of external and internal SRPs. The case of enterprises that perceive high and low influence of external SRPs (Group 1E and Group 2E, respectively) is particularly interesting as there are statistically significant differences with respect to the perception of the risk taken by them.

The analysis of the differential functioning (DIF) shows that managers that perceive higher and lower influence of internal SRPs and who have the same attitude to risk, give importance to the same type of strategic choices. Both strategic choices and risk attitude coincide in the groups of enterprises that perceive more influence and those that perceive less influence of internal SRPs.

It is more coherent to find differences in the type of strategic choices considered important for the managers when they perceive higher or lower influence of external SRPs 
Table 3. Importance of strategic choices

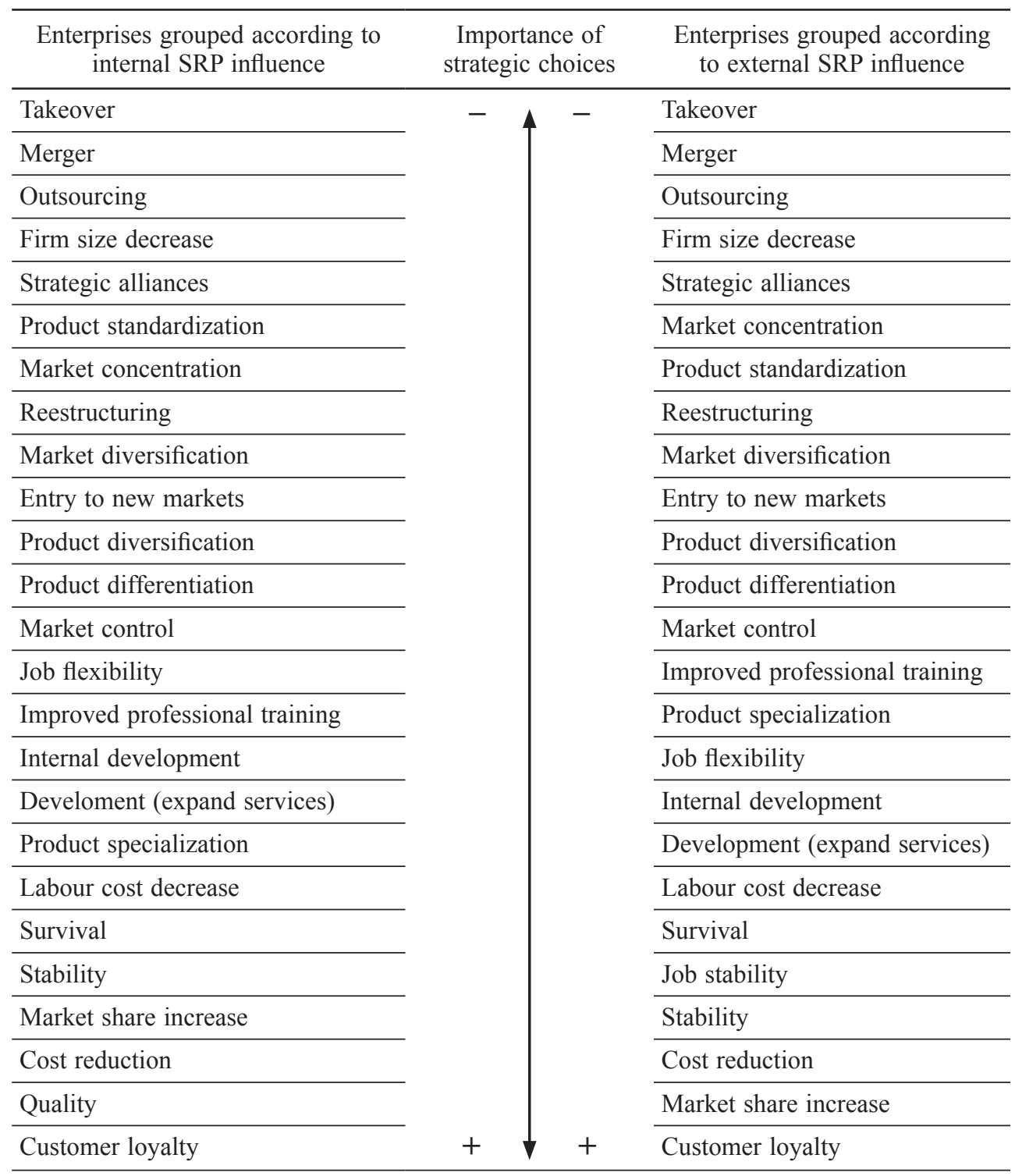

Table 4. Differences between the importance of strategic choices according to the influence of external SRPs

\begin{tabular}{lccccc}
\hline \multicolumn{1}{c}{ Strategic choices } & \multicolumn{2}{c}{$\begin{array}{c}\text { Group 1E (High influence } \\
\text { external SRPs) }\end{array}$} & \multicolumn{2}{c}{$\begin{array}{c}\text { Group 2E(Low influence } \\
\text { external SRPs) }\end{array}$} & Prob \\
\cline { 2 - 5 } & DIF measure & DIF S.E. & DIF measure & DIF S.E. & \\
\hline Market diversification & 0.17 & 0.11 & 0.59 & 0.14 & 0.0219 \\
\hline Job flexibility & -0.05 & 0.12 & -0.47 & 0.15 & 0.0331 \\
\hline
\end{tabular}


and, consequently, higher and lower risk. Table 4 shows that there are differences only in market diversification and job flexibility. Those decision makers who perceive higher influence of external SRPs (Group 1E) and feel they take more risks make this clear by giving more importance to the search for new markets, a risky strategic choice (Table 2). Whereas those managers who perceive lower influence of external SRPs (Group 2E) and feel they take fewer risks insist on creating more flexible labour structures (Table 4 ), considered a less risky choice (Table 2). Thus hypothesis 4 is confirmed but not hypothesis 3 .

\section{Conclusions}

The empirical integration of prospect theory (Kahneman, Tversky 1979) and SRP theory (Fiegenbaum et al. 1996) has allowed us to fill a gap in the literature and present a more realistic view of the strategic decision making process. In the context of SMEs, it makes more sense because of the importance of the managers' role and their perceptions in these enterprises' decision making. This fact has allowed us to discover the position of enterprises with respect to their internal and external SRPs and the consequences for their strategic choices by means of analysing the strategic risk taken by decision makers. This initial approximation shows us that the influences of each of the dimensions on risk do not follow the same trend: greater influence of external SRPs increases the risk taken, but not a greater influence of internal SRPs. Therefore, it will be necessary to study in more depth how the influence of each dimension develops a possible predominance as a determining factor of risk. Thus, it would be important to continue studying the possible differences in the link between SRPs and risk depending on the nature of the SRPs, internal or external.

With respect to strategic choices (Table 4), all four groups coincide closely in those choices they regard as important. Most of these strategic choices are not very risky, such as cost reduction, customer loyalty, increase in market share, stability or survival. They also agree on the strategic choices they do not give importance to, among which are takeovers, decrease in firm size, outsourcing, strategic alliances, mergers... many of them quite risky, although necessary for a kind of firm whose small size, poor resource availability and limited negotiating power make it a good candidate to undertake collective actions with other firms.

The enterprises of the study are, in general, conservative firms in their attitude and their strategic choices. The exception is the group of firms that focus their attention outside, which perceive they are taking risks, giving more importance than the other enterprises to market diversification. This strategic choice therefore conditions the difference in risk perception taken by the two groups of enterprises.

This conservatism by enterprises could demonstrate, among other things, the need for their managers to rethink their SRPs, which perhaps have stated the same for too long. When dealing with SMEs, their management often falls to a single person who does not have a management team available with diverse and heterogeneous SRPs, thus debates or discussions about them do not arise. 
This study has several important implications. For managers, the study of the SRPs shows a large number of enterprises with a more internal than external view. Thus, the need for rethinking their SRPs and for designing a greater market orientation of firms in the service sector is worth highlighting.

There are also important implications for the public administration and institutions. They should emphasize the promotion of cooperation among enterprises to increase their external orientation and then, the importance of external SRPs. Training, financial and organizational support could be some of the strategies that ought to be implemented. Future studies could continue to investigate in greater depth some aspects of this integrative perspective like classifying enterprises into four exclusive groups according to the level of influence of internal or external SRPs, analyzing the implications of that influences on the SMEs results and including the temporal dimension of SRPs.

\section{Acknowledgements}

The authors received financial support from the "Promotion of Business Research in the Canary Islands' Universities 2010" (FydeCajaCanarias and Canary Islands' Government). The authors specially thank Avi Fiegenbaum for his helpful comments on an earlier draft of this paper.

\section{References}

Andrich, D. 1988. Rasch models for measurement. Newbury Park, California: Sage.

Bamberger, P.; Fiegenbaum, A. 1996. The role of strategic reference points in explaining the nature and consequences of human resources strategy, Academy of Management Review 21(4): 926-958.

Bond, T. G.; Fox, C. H. M. 2007. Applying the rasch model. Fundamental measurement in the human sciences. Mahwah, NJ: Erlbaum.

Confederación Canaria de Empresarios. 2006. Informe anual de la economía canaria. Las Palmas de Gran Canaria: Confederación Canaria de Empresarios.

Das, T. K.; Teng, B. 1999. Cognitive biases and strategic decision processes: an integrative perspective, Journal of Management Studies 36(6): 757-778.

http://dx.doi.org/10.1111/1467-6486.00157

Engelhard, G. 1984. Thorndike, Thurstone and Rasch: a comparison of their methods of scaling psychological and educational test, Applied Psychological Measurement 8(1): 21-38.

http://dx.doi.org/10.1177/014662168400800104

Escribá-Estévez, A.; Sánchez-Peinado, L.; Sánchez-Peinado, E. 2008. Moderating influence on the firm's strategic orientation-performance relationship, International Small Business Journal 26(4): 463-489. http://dx.doi.org/10.1177/0266242608091174

Fiegenbaum, A.; Hart, S.; Schendel, D. 1996. Strategic reference point theory, Strategic Management Journal 17: 219-235.

http://dx.doi.org/10.1002/(SICI)1097-0266(199603)17:3<219::AID-SMJ806>3.0.CO;2-N

Fischer, A. R. H.; Frewer, L. F.; Nauta, M. J. 2006. Toward improving food safety in the domestic environment: a multi-item Rasch scale for the measurement of the safety efficacy of domestic food-handling practices, Risk Analysis 26(5): 1323-1338.

http://dx.doi.org/10.1111/j.1539-6924.2006.00813.x 
García-Pérez, A.; Yanes-Estévez, V.; Oreja-Rodríguez, J.R. 2012. Perceived environmental uncertainty and strategic alliances in small and medium-sized enterprises, International Journal of Entrepreneurship and Small Business 17 (3): 355-377. http://dx.doi.org/10.1504/IJESB.2012.049582 Ginsberg, A. 1990. Connecting diversification to performance: a sociocognitive approach, Academy of Management Review 15(3): 514-535. http://dx.doi.org/10.5465/AMR.1990.4309115 http://dx.doi.org/10.2307/258021

Heath, C.; Larrick, R. P.; Wu, G. 1999. Goals as reference points, Cognitive Psychology 38: 79-109. http://dx.doi.org/10.1006/cogp.1998.0708

Helfat, C. E.; Peteraf, M. A. 2014. Managerial cognitive capabilities and the microfoundations of dynamic capabilities, Strategic Management Journal, in press. http://dx.doi.org/10.1002/smj.2247

Holmes, R. M.; Bromiley, P.; Devers, C. E.; Holcomb, T. R.; McGuire, J. B. 2011. Management theory applications of prospect theory: accomplishments, challenges and opportunities, Journal of Management 37 (4): 1069-1107. http://dx.doi.org/10.1177/0149206310394863

Janney, J. J.; Dess, G. G. 2006. The risk concept for entrepreneurs reconsidered: new challenges to the conventional wisdom, Journal of Business Venturing 21: 385-400.

http://dx.doi.org/10.1016/j.jbusvent.2005.06.003

Jansen, R. J. G.; Curşeu, P. L.; Vermeulen, P. A. M.; Geurts, J. L. A.; Gibcus, P. 2011. Information processing and strategic decision-making in small and medium-size enterprises: the role of human and social capital in attaining decision effectiveness, International Small Business Journal 31(2): 192-216. http://dx.doi.org/10.1177/0266242611406762

Jones, R. M.; Kashlak, R. J. 2001. Socio-regulatory upheaval, reference points and strategic evolution of the cigarette industry, Journal of Business Research 51: 193-200.

http://dx.doi.org/10.1016/S0148-2963(99)00053-3

Kahneman, D.; Tversky, A. 1979. Prospect theory: an analysis of decision under risk, Econometrica 47(2): 263-291. http://dx.doi.org/10.2307/1914185

Kotlar, J.; De Massis, A.; Fang, H.; Frattini, F. 2014. Strategic reference points in family firms, Small Business Economics, in press. http://dx.doi.org/10.1007/s11187-014-9556-6

Lavie, D.; Fiegenbaum, A. 2003. The dominant strategic positioning of foreing mncs: a typological approach and the experience of Israeli industries, Journal of Business Research 56: 805-814. http://dx.doi.org/10.1016/S0148-2963(02)00468-X

Lev, S.; Fiegenbaum, A.; Shoham, A. 2009. Managing absorptive capacity stocks to improve performance: empirical evidence from the turbulent environment of Israeli hospitals', European Management Journal 27: 13-25. http://dx.doi.org/10.1016/j.emj.2008.04.001

Linacre, J. M. 2002. What do infit and outfit, mean-square and standardized mean?, Rasch Measurement Transactions 16(2): 878.

Linacre, J. M. 2004. Estimation methods for Rasch measures, in Jr. E. V. Smith, R. M. Smith (Eds.). Introduction to Rasch measurement. Theory, models and applications. Maple Grove, MN: JAM Press, 25-47.

Linacre, J. M. 2007. Winsteps. Rasch measurement computer program [online], [cited 23 January 2012] Winsteps.com. Chicago. Available from Internet: http://www.winsteps.com/winman/ index.htm

McNamara, G.; Bromiley, P. 1999. Risk and return in organizational decision making, Academy of Management Journal 42(3): 330-339. http://dx.doi.org/10.2307/256923

Neuman, W. L. 1997. Social research methods. Qualitative and quantitative approaches. Needham Heights, MA: Allyn and Bacon.

Nunnally, J. C. 1987. Teoría Psicométrica. Méjico: Trillas. 
Nwogugu, M. 2005. Toward multi-factor models of decisión making and risk. A critique of Prospect Theory and related approaches, part I, The Journal of Risk Finance 6(2): 150-162.

http://dx.doi.org/10.1108/15265940510585815

Osiyevskyy, O.; Dewald, J. 2014. Inducements, impediments and immediacy: exploring the cognitive drivers of small business managers' intentions to adopt business model change, Journal of Small Business Management, in press. http://dx.doi.org/10.1111/jsbm.12113

Parnell, J. A.; Lester, D. L.; Menefee, M. L. 2000. Strategy as a response to organizational uncertainty: an alternative perspective on the strategy-performance relationship, Management Decision 38(8): 520-530. http://dx.doi.org/10.1108/00251740010352811

Porter, M. E. 1980. Competitive strategy. New York: The Free Press.

Rasch, G. 1980. Probabilistic models for some intelligence and attainment tests. Chicago: University of Chicago Press.

Salzberger, T. 2009. Measurement in marketing research: an alternative framework. Northampton: Edward Elgar.

Shapira, Z. 1994. Risk taking. A managerial perspective. New York: Russell Sage Foundation.

Shinkle, G. A. 2012. Organizational aspirations, reference points, and goals: building on the past and aiming for the future, Journal of Management 38(1): 415-455.

http://dx.doi.org/10.1177/0149206311419856

Wang, X. T. 2008. Risk communication and risky choice in context: ambiguity and ambivalencehypothesis, Annals of the New York Academy of Sciences 1128: 78-89.

http://dx.doi.org/10.1196/annals.1399.009

Williams, T. 1995. A classified bibliography of recent research relating to project risk management, European Journal of Operational Research 85: 18-38.

http://dx.doi.org/10.1016/0377-2217(93)E0363-3

Wright, B.; Mok, M. M. C. 2004. An overview of the family of Rasch measurement models, in E. V. Jr. Smith, R. M. Smith (Eds.). Introduction to Rasch measurement, theory and applications. Maple Grove, Minnesota: JAM Press, 1-24.

Wright, B.; Stone, M. 1999. Measurement essentials. Wilmington, Delaware: Wide Range Inc.

Zikmund, W. G.; Babin, B. J.; Carr, J. C.; Griffin, M. 2010. Business research methods. United Kingdom: South-Western, Cencage Learning.

Ana María GARCÍA-PÉREZ is an Associate Professor of Strategic Management at the Universidad de La Laguna (Spain). She received a prize for her doctoral dissertation from the Canary Government in 2002. Her research focuses on agri-food supply chain strategic management and strategic behaviour.

Vanessa YANES-ESTÉVEZ is an Associate Professor of Business Administration at the Universidad de La Laguna (Spain). Her research focuses on environmental scanning, strategic risk and strategic management from a cognitive perspective.

Juan Ramón OREJA-RODRÍGUEZ is a Full Professor of Strategy Management at the Universidad de La Laguna (Canary Islands-Spain). His research focuses on the cognitive approach to management: Competitive analysis, environmental scanning, uncertainty and risk in decision making, strategy formulation; methodology of the objective measurement (IRT-Rasch models) and service firms. 